\title{
Determinants of iodine deficiency among school age children in Guraghe Zone, Southwest Ethiopia
}

\author{
Berhanu Abebaw ${ }^{1}$, Abdu Oumer ${ }^{2}$ \\ ${ }^{1}$ Department of Nutrition and Dietetics, School of Public Health, Bahir Dar University, Ethiopia \\ ${ }^{2}$ Department of Public Health, College of Health Science and Medicine, Wolkite University, Ethiopia
}

\section{Article Info \\ Article history: \\ Received Nov 18, 2019 \\ Revised Apr 15, 2020 \\ Accepted Apr 24, 2020}

\section{Keywords:}

Goiter

Iodine deficiency

School age

Southwest

\begin{abstract}
Globally, insufficient iodine intake is found to be the most common preventable cause of mental retardation that results in diminished immunity, decreased school performance and infant and young child death. Ethiopia is the first of the top iodine deficient countries in the world. About 12 million children (school age) get inadequate iodine. Community based cross sectional study was conducted on 792 school age children in Guraghe Zone, Ethiopia to assess the determinants of iodine deficiency. Multistage sampling technique was used to select the study subjects. Data were collected by using pretested questionnaire. Clinical examinations were taken following standard procedures. The collected data were entered into Epi-data and exported to SPSS for analysis. Descriptive statistics was calculated and presented accordingly. Bivariate and multivariable Logistic regression with odds ratios along with the $95 \%$ confidence interval was computed and interpreted accordingly. A P-value $<0.05$ was declared as statistically significant association. Total goiter rate was $8.7 \%$. Factors that had significant association with goiter were: School age children who utilized non iodized salt $(\mathrm{AOR}=3.12,95 \% \mathrm{CI}=1.73-5.63)$, those who consumed cabbage $>2$ times per week $(\mathrm{AOR}=1.94,95 \% \mathrm{CI}=1.10-3.52)$, and children who got elder (AOR=1.22, 95\% CI=1.10-1.41). The study area had mild iodine deficiency disorder. Non iodized salt utilization; frequent cabbage consumption and increased age of children were found to be predictors of goiter. Thus, Interventions should focus on universal salt iodization, besides familiarizing goiterogens to the community at large.
\end{abstract}

This is an open access article under the CC BY-SA license.

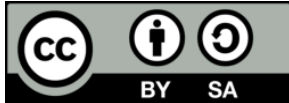

\section{Corresponding Author:}

Berhanu Abebaw,

Department of Nutrition and Dietetics,

School of Public Health,

Bahir Dar University, Ethiopia.

Email: birhanua20@gmail.com

\section{INTRODUCTION}

Iodine is a critical component of thyroid hormones which are necessary for optimal brain development and function; moreover, it controls metabolic rate and the growth and development of body structures during pregnancy [1]. The optimal daily iodine intake for school children (6-12years) is 120gram, as recommended by world health organization (WHO) [2]. Globally, insufficient iodine intake is found to be the most common preventable cause of mental retardation and brain damage $[1,2]$.

Iodine deficiency (ID) is largely caused by low iodine content in the foods that people consumed [3]. Iodine status is known to be directly related to intake [4] and the major source of iodine is utilization of iodized salt [5]. ID results in diminished immunity, decreased school performance and infant and young child death $[6,7]$. Thyroid enlargement can be estimated by palpation (clinically) or ultrasound and is the most easily 
detected sign of iodine deficiency [8]. All the adverse consequences attributed to ID are together called iodine deficiency disorders (IDD). These disorders include stillbirth, miscarriage, cretinism, goiter, mental retardation and hypothyroidism [9, 10]. The most severe consequences of ID are increased perinatal death and mental retardation [11]. IDD is a global public health issue that touches around one fourth of the world's population [12]. Pregnant women and children (6-12 years) are the most vulnerable groups for ID [13]. To eliminate IDD, universal salt iodization (USI) programs were given a major emphasis in the global approach since 1990 [14]. Globally $29.8 \%$ of school age children (241 million) are estimated to have insufficient iodine intakes. Southeast Asia has the largest number of school age children with low iodine intakes (76 million) and $39 \%$ (58 million) have inadequate iodine intakes in Africa [15].

In Ethiopia, IDD have been documented as the most important public health problem for the last six decades and continue to be a major threat to its people [16-19]. Despite implementing USI programs, Ethiopia is the first of the top iodine deficient countries in the world; about 66 million people are prone to the risk of IDD. Moreover, 12 million children (school age) get inadequate iodine. ID causes 37.3 cretins, 33.4 miscarriage, and 47.5 stillbirths and neonatal deaths per 1000 live births $[15,20]$. The nation's education is questionable, as ID may cause an intelligence quotient (IQ) reduction of 13.5 points [21]. This problem has been estimated at nearly 1 billion (US\$) loss over the 2000-2005. In Ethiopia, only less than 1/5th of the households used adequately iodized salt; more than 4 million children $(39.9 \%)$ had goiter. Even though variations of goiter rate occur among regions; in SNNPR the problem accounts to 56\% in school age children [22]. Despite the fact that highest prevalence of goiter (among school age children) in SNNPR compared to other regions in Ethiopia, very little has been given in terms of intervention activities and etiologic investigations. Assessing the problem of iodine deficiency has a great importance to know the effectiveness and design appropriate strategies. However literature is scanty, particularly in the study area. Thus, this study aimed to assess the determinants of ID among school children (6-12 years) in Guraghe zone, southwest Ethiopia.

\section{METHODS AND MATERIALS}

\subsection{Study setting}

The study was conducted in Guraghe zone, one of the zones in SNNPR, Ethiopia from February 21 to March 20/2018. The zone has 13 woredas and 2 town administrations; Wolkite town is its capital, and found $425 \mathrm{kms}$ and $153 \mathrm{kms}$ from Hawassa (the capital of SNNPR) and Addis Ababa (capital city of Ethiopia) respectively. Community based cross sectional study design using quantitative methods was employed.

\subsection{Populations}

All households with school children (6-12 years) in Guraghe zone, in 2017/18 academic year were the source populations. All randomly selected households with school aged children from randomly selected Kebeles in Guraghe zone were the study populations. All randomly selected school age children from selected households were eligible for the study.

\subsection{Sample size determination}

The size was calculated using single population proportion formula with $95 \% \mathrm{CI}$, critical value $(\mathrm{Z})$ as $1.96,5 \%$ marginal error $(\mathrm{d})$ and taking prevalence of goiter among children aged 6-12 (P) from study done in Ethiopia [22] as 56\%. Hence, the sample size (n) became 377; since the sampling technique is multistage, we used design effect of 2 . Accordingly, $N=377 * 2=754$. Adding $5 \%$ non-response rate, the final sample size $(N)=754+(754 * 0.05)=792$.

\subsection{Sampling technique and procedure}

Multistage sampling technique was used to select the study participants. Out of the total woredas in the zone, 5 woredas were randomly selected using simple random sampling (SRS) technique. Then from each woreda, two kebeles were randomly selected using SRS (one from urban and one from rural, as salt iodization varies). The sample size was proportionally allocated to each woreda and kebele according to the expected number of children. After identifying the geographic proximate center of the kebeles, spinning the pen technique was applied to select the households. Then all households in the direction of a pen were checked for eligible children and the interview was held accordingly. When the required sample size was not reached, another spinning was done and eligible children were interviewed until the respective sample size gotten.

\subsection{Data collection tool and data collectors}

The questionnaire was adapted from different peer reviewed literatures and efforts were made to incorporate all the important variables. Furthermore, the tool was translated to the local language. The trained nurses did the interview using a pretested interviewer administered questionnaire. In addition, they did the clinical examination to check whether or not children develop goiter (the outcome variable). Assessment of wealth index was made using ownership of different assets. 


\subsection{Variables of the study}

Goiter is the outcome variable. The independent variables include socio-demographic characteristics, wealth index, dietary diversity, iodized salt utilization, intake of goiterogens, and others. Total Goiter prevalence is the sum of children who have Grade 1 and Grade 2 goiter by physical examination. Grade 0 indicates no palpable goiter or visible goiter. Grade 1 indicates palpable but not visible goiter when neck is in normal position. Grade 2 indicates a clearly visible goiter on inspection [23].

\subsection{Data quality control}

To assure data quality, training of the data collectors was done before the data collection. Close supervision was made by the investigators and assigned supervisors (Public health officers). Pretest was done in $5 \%$ of the sample. After the pretest, necessary amendments were made in the tool. The daily collected data were checked for its consistency and completeness.

\subsection{Data processing and analysis}

The data were entered twice in to Epi-data version 3.01 software, and comparison was made against the hard copy and corrected accordingly. The entered data were exported to SPSS version 22 for analysis. Descriptive statistics was shown using frequency, percentage, and others. TGP was calculated based on the alternative occurrence of Grade 1 and 2 on physical examination finding. Goiter prevalence was modeled using statistics under binary outcome using binary logistic regression analysis. Thus, both bivariate and multivariable binary logistic regressions were performed. COR and AOR with 95\% CI was calculated. Then a statistical association with p-value $<0.05$ was declared as statistically significant. The Hosmer and Lemeshow's test was calculated to assess the model fitness, a P-value $>0.05$ as fit regression model.

\subsection{Ethical considerations}

Ethical clearance was taken from ethical review board of Wolkite University and letter of approval was taken from the zonal health office and accordingly, from the woredas. Before the interview, informed written consent was taken from the parents of children and verbal assent was taken from children. For all the gathered information, confidentiality was kept. The nature of the study design might lead to temporal bias between the possible exposures effect on the occurrence of goiter.

\section{RESULTS AND DISCUSSION}

\subsection{Socio-demographic and economic characteristics of children}

A total of 762 school age children were participated making the response rate, $96.2 \%$. About 447 (58.7\%) of study participants were males. The vast majority, 645(84.6\%) of study subjects' care givers were fathers. More than two fifth $(43.3 \%)$ of the study subjects' households were farmers. More than quarters (196) of the study subjects' caregivers were illiterate. The mean age of school age children was 8.1 years as shown in Table 1. Nearly one fifth (19.9\%) of the study subjects were found to be among the poorest (as indicated by the wealth index quantiles of households) and about $176(23.1 \%)$ were found to be among the wealthiest group.

Table 1. Socio demographic characteristics of children and their care givers

\begin{tabular}{cccc}
\hline Variables & Category & Frequency & Percentage \\
\hline Sex of child & Male & 447 & 58.7 \\
& Female & 315 & 41.3 \\
Care giver & Total & 762 & 100 \\
& Father & 645 & 84.6 \\
& Care givers & 110 & 14.4 \\
& Others & 7 & 0.9 \\
Occupation of household head & Total & 762 & 100 \\
& Farmers & 330 & 43.3 \\
& Merchant & 195 & 25.6 \\
& Governmental & 150 & 19.7 \\
& Daily workers & 61 & 8.0 \\
& Others & 26 & 3.4 \\
Educational status of mother or care giver & Total & 762 & 100 \\
& Illiterate & 196 & 25.7 \\
& Read and write & 181 & 23.8 \\
& Elementary school & 240 & 31.5 \\
& High school & 64 & 8.4 \\
& Higher institution & 81 & 10.6 \\
& Total & 762 & 100 \\
\hline
\end{tabular}

Int. J. Public Health Sci, Vol. 9, No. 2, June 2020: 90 - 96 


\subsection{Prevalence of Goiter and Its predictors among school age children}

In this study, the total goiter prevalence was $8.7 \%$ which indicates a mild iodine deficiency disorder [24]. Eight percent, CI $(6.2 \%-10.1 \%)$ and $0.7 \%$, CI $(0.1 \%-1.3 \%)$ of the study subjects were having Grade 1 and Grade 2 goiter respectively. To know the association of predictor variables with goiter status, both bivariate and multivariable analysis were done. In the bivariate analysis, seven variables: age of the child, type of salt used, turnip intake, cabbage intake, soya bean intake, DDS level, and intake of milk and milk products showed an association with goiter at p-value $<0.2$ and they were a candidate for multivariable logistic regression analysis as shown in Table 2.

Among the variables entered to multivariable logistic regression, age of the child, type of salt used, and cabbage intake were significantly associated with goiter. The comparison of school age children, (those who had goiter and those who had not); School age children who utilized non iodized salt were 3.12 times more likely to develop goiter than those who utilized iodized salt $(A O R=3.12,95 \% C I=1.73-5.63)$. School age children who consumed cabbage more than two times were 1.94 times more likely to develop goiter than those who never consumed or consumed 1-2 times per week $(A O R=1.94,95 \% C I=1.10-3.52)$. School age children who got elder were 1.22 times more likely to develop goiter, compared to their counterparts $(A O R=1.22,95 \% C I=1.10-1.41)$ as shown in Table 3 .

Table 2. Cross tabulation and binary logistic regression that shows the association of variables with goiter

\begin{tabular}{|c|c|c|c|c|c|}
\hline \multirow{2}{*}{ Variables } & \multirow{2}{*}{ Category } & \multicolumn{2}{|c|}{ Goiter status } & \multirow{2}{*}{ COR $(95 \% \mathrm{CI})$} & \multirow{2}{*}{$P$-value } \\
\hline & & Yes & No & & \\
\hline \multirow{2}{*}{ Child sex } & Male & 34 & 413 & 1 & \\
\hline & Female & 32 & 283 & $1.37(0.83,2.28)$ & 0.219 \\
\hline Age & \multicolumn{3}{|c|}{ Per each unit increase in age } & $1.19(0.96,1.48)$ & 0.119 \\
\hline \multirow{5}{*}{ Wealth Index } & Lowest & 2 & 150 & $0.15(0.03,0.69)$ & 0.014 \\
\hline & Second & 18 & 135 & $1.54(0.74,3.22)$ & 0.247 \\
\hline & Middle & 21 & 126 & $1.93(0.94,3.94)$ & 0.072 \\
\hline & Fourth & 11 & 123 & $1.04(0.45,2.36)$ & 0.935 \\
\hline & Wealthiest & 14 & 162 & 1 & \\
\hline \multirow{2}{*}{ Type of salt used } & Iodized salt & 20 & 445 & 1 & \\
\hline & Non iodized salt & 46 & 251 & $4.10(2.36,7.10)$ & 0.000 \\
\hline \multirow{2}{*}{ Child receive any iodine } & Yes & 16 & 199 & 1 & \\
\hline & No & 50 & 497 & $1.25(0.70,2.25)$ & 0.454 \\
\hline \multirow{2}{*}{ Turnip intake } & $>2$ times week & 23 & 113 & $2.76(1.60,4.76)$ & 0.000 \\
\hline & $\leq 2$ times per week & 43 & 583 & 1 & \\
\hline \multirow{2}{*}{ Kale } & $>2$ times week & 44 & 387 & $1.60(0.94,2.72)$ & 0.885 \\
\hline & $\leq 2$ times per week & 22 & 309 & 1 & \\
\hline \multirow{2}{*}{ Cabbage } & $>2$ times week & 21 & 117 & $2.31(1.33,4.02)$ & 0.003 \\
\hline & $\leq 2$ times per week & 45 & 579 & 1 & \\
\hline \multirow{2}{*}{ Soya bean } & $>2$ times week & 5 & 25 & $2.20(0.81,5.95)$ & 0.121 \\
\hline & $\leq 2$ times per week & 61 & 671 & 1 & \\
\hline \multirow{2}{*}{ DDS level } & Inadequate DD & 53 & 391 & $3.18(1.70,5.94)$ & 0.001 \\
\hline & Adequate DD & 13 & 305 & 1 & \\
\hline \multirow{2}{*}{ Maternal Iodine knowledge } & Poor knowledge & 33 & 322 & $1.16(0.70,1.93)$ & 0.561 \\
\hline & Good knowledge & 33 & 374 & 1 & \\
\hline \multirow{2}{*}{ Sea foods } & Yes $(\geq 1$ times/week) & 3 & 41 & 1 & \\
\hline & No (never in a week) & 63 & 655 & $1.32(0.40,4.37)$ & 0.655 \\
\hline \multirow{2}{*}{ Milk and milk products } & Adequate intake & 12 & 236 & 1 & \\
\hline & Inadequate intake & 54 & 460 & $2.31(1.21,4.40)$ & 0.011 \\
\hline
\end{tabular}

Table 3. Multivariable logistic regression that shows significant predictors of goiter

\begin{tabular}{|c|c|c|c|c|c|}
\hline \multirow{2}{*}{ Variables } & \multirow{2}{*}{ Category } & \multicolumn{2}{|c|}{ Goiter status } & \multirow{2}{*}{ AOR $95 \% \mathrm{CI}$} & \multirow{2}{*}{$P$-value } \\
\hline & & Yes & No & & \\
\hline Age & \multicolumn{2}{|c|}{ Per each unit increase in age } & & $1.22(1.10,1.41)$ & $0.008^{*}$ \\
\hline \multirow{2}{*}{ Type of salt used } & Iodized salt & 20 & 445 & 1 & \\
\hline & Non iodized salt & 46 & 251 & $3.12(1.73,5.63)$ & $0.001 *$ \\
\hline \multirow[t]{2}{*}{ Turnip intake } & $>2$ times a week & 23 & 113 & $1.85(1.03,3.31)$ & 0.039 \\
\hline & $\leq 2$ times per week & 43 & 583 & 1 & \\
\hline \multirow{2}{*}{ Cabbage } & $>2$ times week & 21 & 117 & $1.94(1.10,3.52)$ & $0.028^{*}$ \\
\hline & $\leq 2$ times per week & 45 & 579 & 1 & \\
\hline \multirow[t]{2}{*}{ Soya bean } & $>2$ times a week & 5 & 25 & $2.76(0.95,8.10)$ & 0.063 \\
\hline & $\leq 2$ times per week & 61 & 671 & 1 & \\
\hline \multirow[t]{2}{*}{ DDS level } & Inadequate DD & 53 & 391 & $1.92(0.98,3.79)$ & 0.058 \\
\hline & Adequate DD & 13 & 305 & 1 & \\
\hline \multirow{2}{*}{ Milk and milk products } & Adequate intake (>3 times/week) & 12 & 236 & 1 & \\
\hline & Inadequate intake ( $\leq 3$ times/week) & 54 & 460 & $1.34(0.67,2.71)$ & 0.405 \\
\hline
\end{tabular}




\title{
3.3. Discussion
}

Globally, iodine deficiency (ID) is the most common avertable cause of brain impairment. On the other hand, iodine deficiency disorder (IDD) is among the easiest and cheapest of all nutrient disorders to prevent. To prevent IDD, utilization of iodized salt in a daily basis is found to be effective. The elimination of IDD is a serious issue that should be given the highest priority by the concerned bodies. This study revealed that the total goiter prevalence of $8.7 \%$. According to ICCIDD a total goiter rate of 5\% in children (6-12 years) is an indicative of a public health risk of adverse functional consequences and need to be addressed [24]. The total goiter prevalence in the study area is lower than the previous studies done in the region (SNNPR) 35.2\% [25] and 50.6\% [26], this difference may be due to variations in soil composition; dissimilarities in the intake of goiterogens that may affect thyroid function, the time gap between the studies and increased awareness about the importance of iodized salt consumption. In addition the studies done in SNNPR [25, 26] were in areas where drinking water has substantial bacterial contamination, which may exacerbate the possibility of goiter [27]. The study was also lower than the studies done in other regions of the country; 62.1\% [28] in Amhara region which is highland area with poor nutrient and eroded soils [29]; 37.2\% [30] in Oromia region, and 23.2\% [31] in Addis Ababa. Similarly, a systematic review in Ethiopia (on progress in eliminating iodine deficiency) and a large survey (among school children in Ethiopia) revealed child goiter prevalence of 35\% [32] and iodine deficiency of 48\% [33] respectively. Even though the prevalence is lower than other studies, still appropriate interventions are required to alleviate the public health risks of adverse functional consequences as indicated by ICCIDD.

Consumption of non iodized salt had significant association with the development of goiter. Children who utilized non iodized salt were 3.12 times more likely to develop goiter than those children who utilized iodized salt. This finding is consistent with many other studies done previously. As it is known, universal salt iodization is the best way to prevent goiter and other IDDs. Being aware of the problem, the government of Ethiopia had planned to eradicate ID and to achieve the utilization of adequately iodized salt to $90 \%$ by the year 2015, though significant improvements have not been attained [15]. Therefore, much more effort is needed to work extensively by focusing on the importance of universal salt iodization (through creating awareness about the deleterious effects of using non iodized salt and others).

Frequent consumption of cabbage had significant association with goiter development. School age children who consumed cabbage more than two times were 1.94 times more likely to develop goiter compared to those children who consumed $\leq 2$ times per week. The finding was consistent with other previous studies done in the country $[25,26,34]$. Frequent consumption of goiterogens like cabbage can negatively affect iodine absorption. This finding is much more plausible since consumption of goiterogenic foods such as cabbage and cassava increase concentrations of thiocyanate, which might interfere with iodine transport [35]. In recent studies the morphological changes after prolonged consumption of goiterogenic foods were characterized by replacement of colloid containing follicles that indicate hypertrophy and hyperplasia. These alterations were also accompanied by inhibition of thyroid peroxidase and $5^{\prime}$ monodeiodinase with a fall in serum T3 and T4 levels. These anatomical and physiological changes may lead to biochemical hypothyroidism [36-37]. More robust studies should be done and appropriate strategies should be designed to decrease the effects of goiterogens like cabbage (on how to create awareness about goiterogenic foods in the community).

\section{CONCLUSION}

Based on the prevalence of goiter, there is mild IDD in the study area. Non iodized salt utilization; frequent cabbage consumption and increased age of children were found to be predictors of goiter. Thus, interventions should focus on universal salt iodization (increasing the community awareness on the importance and proper use), besides familiarizing goiterogens to the community at large.

\section{ACKNOWLEDGEMENTS}

Our heartfelt thank goes to Wolkite University, for funding the study. We are also grateful for the study subjects for their willingness to participate in the study.

\author{
Abbreviations \\ AOR: Adjusted Odds Ratio; CI: Confidence Interval; COR: Crude Odds Ratio \\ ICCIDD: International Council for the Control of Iodine Deficiency Disorders \\ ID: Iodine Deficiency; IDD: Iodine Deficiency Disorder \\ SPSS: Statistical Package for Social Sciences \\ SNNPR: Southern Nations Nationalities Peoples Representatives \\ TGP: Total Goiter Prevalence; USI: Universal Salt Iodization.
}

Int. J. Public Health Sci, Vol. 9, No. 2, June 2020: 90 - 96 


\section{REFERENCES}

[1] Zimmermann M. B., "The Effects of Iodine Deficiency in Pregnancy and Infancy," Paediatric and perinatal epidemiology, vol. 26, no. Suppl 1, pp. 108-117, 2012.

[2] World Health Organization, "Assessment of Iodine Deficiency Disorders and Monitoring Their Elimination," A Guide For Programme Managers, pp. 1-108, 2007.

[3] De Benoist B., Andersson M., Egli I., Takkouche B., and Allen H., "Iodine Status Worldwide," WHO Global Database on Iodine Deficiency Geneva, World Health Organization, pp. 1-58, 2004.

[4] Chakraborty I., Mazumdar P., Chakraborty P. S., Chattopadhyay G., and Bhowmick K., "Iodine Deficiency Disorder among Pregnant Women in A Tertiary Care Hospital of Kolkata, India," The Southeast Asian Journal of Tropical Medicine and Public Health, vol. 41, no. 4, pp. 989-995, 2010.

[5] Chandra A., Singh L., Debnath A., Tripathy S., and Khanam J., "Dietary Supplies of Iodine \& Thiocyanate in the Aetiology of Endemic Goitre in Imphal East District of Manipur, North East India," The Indian Journal of Medical Research, vol. 128, no. 5, pp. 601-605, 2008.

[6] Zimmermann M., "Key Barriers to Global Iodine Deficiency Disorder Control: A Summary,” ETH Zurich, pp. 1-10, 2007.

[7] Mezgebu Y., Mossie A., Rajesh P., and Beyene G., "Prevalence and Serverity of Iodine Deficiency Disorder among Children 6-12 Years of Age In Shebe Senbo District, Jimma Zone, Southwest Ethiopia," Ethiopian Journal of Health Sciences, vol. 22, no. 3, pp. 196-204, 2012.

[8] Gorstein J., "Goiter Assessment: Help or Hindrance In Tracking Progress In Iodine Deficiency Disorders Control Program?," Thyretain, vol. 11, no. 12, pp. 1201-1202, 2001.

[9] Dugassa B. F., and Negassa A., "Understanding the Ecology of Iodine Deficiency and Its Public Health Implications: The Case of Oromia Region in Ethiopia,” Journal of Community Nutrition and Health, vol. 1, no. 1, pp. 1-17, 2012.

[10] Hashemipour M., Soheilipour F., Keshteli A. H., Siavash M., Amini M., and Kelishadi R., "Association Between Serum Ferritin and Goitre in Iranian School Children," Journal of health, population, and nutrition, vol. 28, no. 2, pp. 137-142, 2010.

[11] World Health Organization, "Urinary Iodine Concentrations for Determining Iodine Status in Populations," English, WHO, pp. 1-5, 2013.

[12] Li S., Fan Y., Chen H., Li X., Wang J., Gu Y., et al., "Is the Current Iodine Content in Edible Salt Appropriate for Eliminating Iodine Deficiency in China," Asia Pacific Journal of Clinical Nutrition, vol. 19, no. 2, pp. 231-235, 2010.

[13] De Benoist B., McLean E., Andersson M., and Rogers L., "Iodine Deficiency in 2007: Global Progress Since 2003," Food and nutrition bulletin, vol. 29, no. 3, pp. 195-202, 2008.

[14] World health Organization, and United Nations Children's Fund, "International Council for Control of Iodine Deficiency Disorders and Their Control Through Salt Iodization,” WHO NUT/94., pp.1-55, 1994.

[15] Andersson M., Karumbunathan V., and Zimmermann M. B., "Global Iodine Status in 2011 and Trends Over the Past Decade," The Journal of Nutrition, vol. 142, no. 4, pp. 744-750, 2012.

[16] Cherinet A., and Kelbessa U., "Determinants of Iodine Deficiency in School Children in Different Regions of Ethiopia," East African Medical Journal, vol. 77, no. 3, pp. 133-137, 2000.

[17] Yinebeb M., Andualem M., and Getenet B., "Prevalence and Severity of Iodine Deficiency Disorders Among Children 6-12 Years Of Age In Shebe Senbo District, Jimma Zone, Southwest Ethiopia," Ethiopian Journal of Health Science, vol. 22, no. 3, pp. 196-204, 2012.

[18] Shawel D., Hagos S., Lachat C. K., Kimanya M. E., and Kolsteren P., "Post-Production Losses in Iodine Concentration of Salt Hamper the Control of Iodine Deficiency Disorders: A Case Study In Northern Ethiopia," Journal of health, population, and nutrition, vol. 28, no. 3, pp. 238-244, 2010.

[19] Bogale A., Abebe Y., Stoecker B. J., Abuye C., Ketema K., and Hambidge K. M., "Iodine Status and Cognitive Function of Women and Their Five Year-Old Children In Rural Sidama, Southern Ethiopia," East African Journal of Public Health, vol. 6, no. 3, 296-299, 2009.

[20] Kidane T., and Woldegebriel A., "Prevalence of Iodine Deficiency Disorder in A Highland District in Tigray," Ethiopian Journal of Health Development, vol. 20, no. 1, pp. 58-59, 2006.

[21] Zimmermann M. B., Connolly K., Bozo M., Bridson J., Rohner F., and Grimci L., "Iodine Supplementation Improves Cognition in Iodine-Deficient Schoolchildren in Albania: A Randomized, Controlled, Double-Blind Study," The American journal of clinical nutrition, vol. 83, no. 1, pp. 108-114, 2006.

[22] Abuye C., Berhane Y., Akalu G., Getahun Z., and Ersumo T., "Prevalence of Goiter In Children 6 To 12 Years of Age in Ethiopia," Food and nutrition bulletin, vol. 28, no. 4, pp. 391-398, 2007.

[23] World Health Organization, "Indicators for Assessing Iodine Deficiency Disorders and Their Control Programmes," report of a Joint WHO/UNICEF/ICCIDD consultation," 1993.

[24] WHO/UNICEF/ICCIDD, "Assessment of Iodine Deficiency Disorders and Monitoring Their Elimination," A Guide for Programme Managers, Third edition, Geneva., pp. 1-19, 2007.

[25] Hibstu D. T., and Tesfaye D. J., "Epidemiology of goiter and its predictors among school age children in Leku town, Southern Ethiopia," Cureent Pediatric Research, vol. 21, pp. 4, pp. 620-626, 2017. 
[26] Wolka E., Shiferaw S., and Biadgilign S., "Epidemiological Study of Risk Factors for Goiter among Primary School children in Southern Ethiopia," Food and Nutrition Bulletin, vol. 35, no. 1, pp. 20-27, 2014.

[27] Gaitan E., Medina P., Derouen T. A., and May S. Z., "Goiter Prevalence and Bacterial Contamination of Water Supplies," The Journal of Clinical Endocrinology and Metabolism, vol. 51, no. 5, pp. 957-961, 1980.

[28] Tigabu E., Bekele K. B., and Dachew B. A., "Prevalence of Goiter and Associated Factors among School Children in Northeast Ethiopia," Epidemiol Health, vol. 39, 2017.

[29] Desta L., "Land Degradation and Strategies for Sustainable Development in the Ethiopian Highlands: Amhara Region," Publisher ILRI (aka ILCA and ILRAD, vol. 32, 2000.

[30] Sime H. K., and Tadesse A. W., "Prevalence of Goiter among School-Age Children in Jimma Town, South West Ethiopia," European Journal of Nutrition and Food Safety, vol. 5, no. 5, pp. 867, 2015.

[31] Emiru S., "Iodine Deficiency in School Aged Children 7-12 Years and Associated Factors in Akaki-Kality Subcity of Addis Ababa, Ethiopia," Tesis-AAU Institutional Repository, 2016.

[32] Gebretsadikan T. M., and Troen A. M., "Progress And Challenges In Eliminating Iodine Deficiency In Ethiopia: A Systematic Review," BMC Nutrition, vol. 2, no. 1, pp. 1-12, 2016.

[33] “Ethiopian National Micro Nutrient Survey," 2016. [Online]. Available: https://www.researchgate.net/publication.

[34] Abebe Z., Gebeye E., and Tariku A., "Poor Dietary Diversity, Wealth Status and Use of Un-Iodized Salt Are Associated With Goiter among School Children: A Cross Sectional Study in Ethiopia," BMC Public Health, vol. 17, no. 1, pp. 44-55, 2017.

[35] Chandra A. K., Mukhopadhyay S., Lahari D., and Tripathy S., "Goitrogenic Content of Indian Cyanogenic Plant Food \& Their in Vitro Anti-Thyroidal Activity,” The Indian Journal of Medical Research, vol. 119, no. 5, pp. 180-185, 2004

[36] Amar K. C., "Iodine, Thiocyanate and the Thyroid," Biochemistry and Pharmacology, vol. 4, no. 3, pp. 171-177, 2015.

[37] Brauer V., Below H., Kramer A., Fuhrer D., and Paschke R., "The Role of Thiocyanate in the Etiology of Goiter in an Industrial Metropolitan Area," European Journal of Endocrinology, vol. 154, no. 2, pp. 229-235, 2006.

Int. J. Public Health Sci, Vol. 9, No. 2, June 2020: 90 - 96 